\title{
Preclinical efficacy and safety evaluation of interleukin-6-knockdown CAR-T cells targeting at CD19
}

\author{
Hairuo Wen ${ }^{1 \#}$, Guitao Huo ${ }^{1 \#}$, Tiantian Hou ${ }^{1 \#}$, Zhe Qu ${ }^{1}$, Juanjuan Sun ${ }^{2}$, Zhou Yu ${ }^{2}$, Liqing Kang ${ }^{2}$, \\ Manhong Wang ${ }^{1}$, Xiaoyan Lou ${ }^{2}$, Lei Yu', Yan Huo ${ }^{1}$ \\ ${ }^{1}$ Key Laboratory of Beijing for Safety Evaluation of Drugs, National Center for Safety Evaluation of Drugs, National Institutes for Food and Drug \\ Control, Beijing, China; ${ }^{2}$ Shanghai Unicar Biomed-Pharmaceutical Technology Co. Ltd., Shanghai, China \\ Contributions: (I) Conception and design: H Wen, T Hou, X Lou, L Yu, Y Huo; (II) Administrative support: X Lou, L Yu, Y Huo; (III) Provision of \\ study materials or patients: J Sun, Z Yu, L Kang, X Lou, L Yu; (IV) Collection and assembly of data: H Wen, G Huo, T Hou, Z Qu, J Sun, Z Yu, L \\ Kang; (V) Data analysis and interpretation: H Wen, G Huo, T Hou, Z Qu, J Sun, Z Yu, L Kang, M Wang; (VI) Manuscript writing: All authors; (VII) \\ Final approval of manuscript: All authors. \\ \#These authors contributed equally to this work. \\ Correspondence to: Yan Huo, PhD. Professor, National Center for Safety Evaluation of Drugs, National Institutes for Food and Drug Control, Beijing \\ 100176, China. Email: yanhuo_nifdc@163.com; Lei Yu, PhD. Professor, Shanghai Unicar Biomed-Pharmaceutical Technology Co. Ltd., No 1525 \\ Minqiang Road, Shanghai, China. Email: ylyh188@163.com.
}

Background: ssCART-19 cells with $s h R N A-I L-6$ gene knockdown were subjected to a comprehensive safety evaluation, including efficacy, toxicity and biodistribution studies in NSG (Prkdc $\left.c^{\text {sid }} I L 2 \operatorname{rg}^{\mathrm{tm} 1} / \mathrm{Bcgen}\right)$ mice.

Methods: NSG mice were administered Raji-Luc and then singly dosed with ssCART-19 cells via intravenous infusion. ssCART-19 DNA fragments were quantified in different tissues by qPCR, and the optical intensity of Raji-Luc was determined for evaluate the efficacy of regular CAR-T and ssCART-19 cells. In toxicity study, clinical symptoms observation, body weight measurements, serum biochemical analysis, human cytokine detection, lymphocytes subsets quantification, necropsy and histopathological examination were performed.

Results: The ssCART-19 DNA was mainly concentrated in the liver within 3 hours, and was widely distributed in most of the organs/tissues for 4 weeks after administration. Chimeric antigen receptor gene modified $\mathrm{T}$ cells (CAR-Ts) were detected in the peripheral blood with a significant increase in number beginning at approximately 3 weeks. ssCART-19 administration resulted in increased of interferon-gamma (IFN- $\gamma$ ), tumor necrosis factor (TNF), interleukin-2 (IL-2), and IL-17A and decreased IL-10 and IL-6 levels. ssCART-19 inhibited the proliferation of Raji-Luc cells in tumor-bearing NSG mice, and reduced the incidence of lymphomas in the liver, kidneys and spleen. It alleviated clinical symptoms caused by tumor cell proliferation in treated animals.

Conclusions: ssCART-19 prolongs the survival time of tumor-bearing mice without obvious risks of immunotoxicity and tumorigenicity. ssCART-19 DNA was found in the brains of treated animals, however no significant central nervous system toxicity was observed. These data were used to support an investigational new drug (IND) application of ssCART-19 for clinical trial in China.

Keywords: Chimeric antigen receptor T cell; biodistribution; toxicity; IL-6 knockdown; cytokine release syndrome (CRS)

Submitted Jun 29, 2021. Accepted for publication Nov 01, 2021.

doi: 10.21037/atm-21-3372

View this article at: https://dx.doi.org/10.21037/atm-21-3372 


\section{Introduction}

Chimeric antigen receptor gene modified $\mathrm{T}$ cells (CAR-Ts) are a type of $\mathrm{T}$ cell that have been engineered to produce a specific antigen recognition domain. These cells can recognize tumor-specific antigens and facilitate the release of perforin, granzyme B, cytokines, etc. to kill the tumor cells (1). CAR-Ts, especially those targeting at CD19, have demonstrated remarkable success and are regarded as a milestone in the treatment of relapsed leukemia that does not respond to standard therapies. For example, CTL019, a CAR-T targeting CD19 achieved a 90\% complete response rate in patients with relapsed/refractory acute lymphocytic leukemia (ALL) (2), and a $57 \%$ response rate in the recurrent/refractory chronic lymphocytic leukemia (3). Following the approval of Yescarta (axicabtagene ciloleucel) and Kymriah (tisagenlecleucel) $(4,5)$ for listing by the FDA in 2017, more than 1,000 CAR-T-based clinical trials have been registered around the world. In China, there were 46 CAR-T IND applications at the end of March 2021. Thirty-there of these targeted CD19, accounting for $78.57 \%$ of all CAR-T IND applications.

Despite this upsurge, recent research has revealed many toxicities induced by CAR-T cells, potentially limiting their use. For instance, cytokine release syndrome (CRS), the offtarget effects, neurotoxicity, and graft-versus-host diseases (GvHD), which could be life-threatening in severe cases (6). Of these, CRS, which is triggered by interactions between tumor target cells and infused CAR-T cells, is the most prominent cause of acute CAR-T-associated toxicity (7). CRS-related toxicities, including fever, were reported in $40-80 \%$ of patients, hypotension was reported in $22-38 \%$ of patients, and pulmonary edema, hypoxia, dyspnea and pneumonitis were reported in $6-15 \%$ of patients. It is universally accepted that interleukin 6 (IL-6) is the core mediator of CRS, and IL-6 receptor blockade was shown to successfully ameliorate the life-threatening CRS in a patient with ALL (8). However, though CAR-T-related neurotoxicity is partially dependent on IL-6 elevation in the brain (9), anti-human IL-6 receptor antibodies, e.g., tocilizumab, cannot pass through the brain-blood barrier. Furthermore, some evidence demonstrated that steroid therapy could markedly decrease CAR-T cell levels, therefore reducing their efficacy (10).

In an attempt to reduce the complications associated with CAR-T therapy, novel CART-19 cells (ssCART-19) with shRNA-IL-6 gene knockdown were previously developed for recurrent/refractory ALL. Patients treated with these
ssCART-19 cells exhibited reduced IL-6 secretion from monocytes due to decreased stimulation by IL- 6 from CAR-T cells (11). Further, ssCART-19 cells have been shown to effectively eliminate infiltrating leukemia cells in the skin, testis (12) and cerebrospinal fluid, with mild and acceptable side effects (13). In order to perform a comprehensive preclinical safety evaluation of ssCART-19 cells, we conducted efficacy, toxicity and biodistribution studies in NOD-Prkdc $c^{\text {scid }} I L 2 r g^{t m 1} / \mathrm{Bcgen}$ (NSG) mice. These data revealed the toxicological and distribution profile of ssCART-19 cells, and supported the IND application of ssCART-19 cells for further clinical trials. We present the following article in accordance with the ARRIVE reporting checklist (available at https://dx.doi.org/10.21037/atm-213372).

\section{Methods}

\section{CAR-T and target cell lines}

The Raji-Luc human B-cell Burkitt lymphoma cell line expressing CD19 for tumor xenografting was a gift from Professor Weijin Huang at the National Institutes for Food and Drug Control. The Raji lymphoma cell line was stably transduced with firefly luciferase (14). Raji-Luc cells were cultured using RPMI 1640 medium with $10 \%$ fetal bovine serum and $1 \%$ penicillin-streptomycin solution at $37^{\circ} \mathrm{C}$ with a supplement of $5 \% \mathrm{CO}_{2}$. Cells were resuspended in $0.9 \%$ $\mathrm{NaCl}$ at a concentration of $2.5 \times 10^{6}$ cells $/ \mathrm{mL}$ for in vivo studies (15).

Regular CAR-T cells against CD19 and ssCART-19 cells with shRNA-IL-6 gene knockdown were generated as previously described $(11,13)$. CAR-T cells, $T$ cells, and buffer (containing human albumin, dextran 40 glucose injection, dimethyl sulfoxide $(5 \%, \mathrm{v} / \mathrm{v})$, glucose sodium chloride injection, and compound electrolyte injection) were provided by Shanghai Unicar Biomed-Pharmaceutical Technology Co. Ltd. (Shanghai, China), and were preserved in liquid nitrogen.

\section{Animals}

All animal experimental procedures were approved by the Institutional Animal Care and Use Committee (IACUC) of the National Center for Safety Evaluation of Drugs (NCSED, IACUC approval No. IACUC-2019-033, IACUC-2019-035, IACUC-2019-050), in compliance with the IACUC Constitution of NCSED, the Guide for 
the Care and Use of Laboratory Animals and AAALAC International's Position Statement. A total of 494 6-weekold specific pathogen free NSG (NOD-Prkdscid $I L 2 \mathrm{rg}^{\mathrm{tm} 1}$ / Bcgen) mice (297 males and 297 females) were purchased from Beijing Biocytogen Co., Ltd [Beijing, China; Animal Certificate No: SCXK (SU) 2016-0004]. Of these, 462 were enrolled in this study. NSG mice are IL2RG knockout animals on a NOD-SCID genetic background. These mice lack mature T cells, B cells and NK cells, and are internationally recognized for their high degree of immunodeficiency and suitability for transplantation of human-derived cells or tissues. Mice with relatively lower body weights were excluded from grouping. For the toxicity study, 340 animals were administrated RajiLuc cells prior to CAR-T dosing and then grouped based on their fluorescence intensities. Animals displaying fluorescence values less than 2 times that of the background $\left(\sim 3.6 \times 10^{6} \mathrm{p} / \mathrm{sec} / \mathrm{cm}^{2} / \mathrm{sr}\right)$ prior to CAR-T administration were not included. The mice were housed in individually ventilated cages (at a density of $2-3$ per cage, the experimental unit was a single animal) in a barrier system at $20-26{ }^{\circ} \mathrm{C}, 40-70 \%$ relative humidity, a 12 -hour lightdark cycle, and cage air exchange of over 50 times per hour. Animals had ad libitum access to rodent feed and sterilized tap water via water bottles, and were quarantined for at least 5 days before grouping. Euthanasia with $\mathrm{CO}_{2}$ inhalation is performed, under the following condition(s) as humane endpoints: (I) more than $20 \%$ body weight(s) was(were) lost within 3 days, or (II) the animal(s) could not eat/drink on its(their) own, or (III) other important physiological function(s) was (were) lost.

\section{Biodistribution study}

Forty-two NSG mice (21 males, 21 females) were first administered Raji-Luc cells $\left(5 \times 10^{5}\right.$ per animal) and then singly dosed 96 hours later with intravenous ssCART-19 at $0.6 \times 10^{7}$ per animal (dosage was calculated in accordance with the proportion of $\mathrm{CAR}^{+} \mathrm{T}$ cells, which was $31.33 \%$ for the batch used, see Figure $1 A$ for an overview of study design). To provide adequate data for the IND application, samples were collected from at least 3 animals of each sex.

Three animals of each sex were anesthetized (by isoflurane inhalation) and sacrificed at 3 hours, and 4, 7, 14, 28, 43 and 56 days following ssCART-19 administration in order to quantify ssCART-19 DNA fragments in different tissues, including blood, uterus, testis, ovaries, epididymis, kidneys, livers, spleen, lungs, heart, brain, stomach, duodenum, colon, bone marrow, adipose tissue and skeletal muscle. In brief, DNA was extracted from various tissues using a Dneasy Blood\&Tissue Kit (Qiagen) following the manufacturer's instructions, and the concentrations of eluted DNA were adjusted to a practical range. The ssCART-19 forward and reverse primer sequences are "CCAGGGTCTCAGTACAGCCAC" and "CGGAGTTTCGTCCTTTCCA", respectively, and the ssCART-19 probe sequence is " $F A M$ CCTCGCTAAGTCGACGCTAGC-MGB". The above primers were designed and synthesized by Sangon Biotech (Shanghai, China). The PCR conditions were: $95{ }^{\circ} \mathrm{C}$ for 10 minutes, followed by 40 cycles of $95^{\circ} \mathrm{C}$ for 15 seconds and $62{ }^{\circ} \mathrm{C}$ for 60 seconds, resulting in a $342 \mathrm{bp}$ ssCART-19 sequence. In this study, we used a TaqMan assay, which employs a pair of primers and a specific fluorescent oligonucleotide probe, and the fluorescent signal intensity detected represents the copy number of the targeted DNA sequence. For each sample, three replicates were analyzed and the average value of these replicates was calculated. Prior to usage in PCR assays, DNA concentrations were measured by NanoDrop One to obtain the genomic DNA content. We then used these concentrations to calculate ssCART-19 copy number per ng genomic DNA.

\section{Pharmacodynamics study}

To study the efficacy of regular CAR-T and ssCART-19, a total of 96 mice (48 males and 48 females) were intravenously administered Raji-Luc cells $\left(5 \times 10^{5}\right.$ per animal $)$ for tumor xenografting. Animals were randomized into 8 groups, with 6 of each sex per group, using a computerbased stratified random order generator (TOXSTAT2006). Approximately 96 hours after the injection of Raji-Luc cells, animals were dosed with $\mathrm{T}$ cells $\left(11.2 \times 10^{6}\right)$, regular CAR-T cells (at dosages of $1 \times 10^{6}, 3 \times 10^{6}$ and $6 \times 10^{6}$ ) and ssCART-19 cells (at dosages of $1 \times 10^{6}, 3 \times 10^{6}$ and $6 \times 10^{6}$ ). The dosages of regular CAR-T and ssCART-19 cells were calculated based on the proportion of $\mathrm{CAR}^{+} \mathrm{T}$ cells, which were $57.70 \%$ and $53.55 \%$ respectively, in the batch used. The $\mathrm{T}$ cell dosage was equivalent to the total number of cells administered to animals in the $6 \times 10^{6}$ ssCART- 19 cell group. Three milligrams of D-luciferin (J\&K Scientific, $30 \mathrm{mg} / \mathrm{mL}$ dissolved in $9 \mathrm{mg} / \mathrm{mL} \mathrm{NaHCO}{ }_{3}, 100 \mu \mathrm{L}$ per animal) was intraperitoneally administered to the mice by intraperitoneal injection to determine the optical intensity of Raji-Luc cells in each animal using IVIS Lumina III (Perkin Elmer). Luminescence intensity was captured at 
$1,3,6,9,13,16$, and 27 days following the administration of regular CAR-T and ssCART-19 cells. Animal survival was observed for 91 days following CAR-T/ssCART-19 administration.

\section{Toxicity study}

To comprehensively assess toxicity, 324 NSG mice were randomized into the untreated group (48 animals), buffer group (36 animals), T cell group (60 animals), ssCART-19 $2 \times 10^{6}$ group (60 animals), ssCART-19 $6 \times 10^{6}$ group (60 animals), and ssCART-19 $20 \times 10^{6}$ group (60 animals) respectively, using a computer-based stratified randomization grouping method (TOXSTAT2006). Fourteen days following CAR-T administration, 12 males and 12 females from each group were sacrificed (except for the untreated group, where 6 animals of each sex were sacrificed). Twenty-eight days following CAR-T administration, 6 males and 6 females from each group were sacrificed. The remaining animals (6 of each sex per group, except the buffer group) were kept until the end of the study for long-term observation and blood sampling. The clinical dose of CD19-positive CAR-T cells is $5 \times 10^{6} / \mathrm{kg}$, which is equivalent to $1 \times 10^{6}$ per animal (the body mass of a mouse is taken as $0.02 \mathrm{~kg}$, and the body surface area is taken as 10 -fold that of a human). In this study, animals were singly dosed with ssCART-19 cells $\left(2 \times 10^{6}, 6 \times 10^{6}\right.$ and $20 \times 10^{6}$ per animal) via intravenous injection (96 h after administration of $5 \times 10^{5}$ cells Raji-Luc cells per animal). Considering that the CD19-positive CAR-T cell rate is estimated to be $34.53 \%$, animals in the $\mathrm{T}$ cells and ssCART-19 $20 \times 10^{6}$ groups were dosed with $5.79 \times 10^{7} \mathrm{~T}$ cells each, which is less than the maximum number of tolerable cells $\left(1 \times 10^{8}\right.$ per animal). The mice in the buffer group were administered an equal volume of freezing buffer, and an untreated group without tumor xenografting was administered freezing buffer in parallel. See Figure $1 B$ for an overview of study design.

To evaluate toxicity, clinical symptoms were observed every day, while animal body weight and Raji-Luc fluorescence intensity were measured every week. Animals were anesthetized (by isoflurane inhalation) and sacrificed (by sodium pentobarbital overdose) 14 and 28 days post CAR-T administration. Serum was biochemically analyzed for parameters including glutamic-pyruvic transaminase (ALT), aspartic acid aminotransferase (AST), alkaline phosphatase (ALP), creatine phosphokinase (CK), lactic dehydrogenase (LDH), total bilirubin (TBIL), and urea nitrogen (UREA) as well as human cytokine profiles [IL-2, IL-4, IL-6, IL-10, interferon-gamma (IFN- $\gamma$ ), tumor necrosis factor (TNF), and IL-17A]. Full necropsy was performed, and the heart, lungs, liver, spleen, kidneys, brain, testis, epididymis, ovaries, uterus, abdomen skin, injection site (tail), duodenum, jejunum, ileum, and bone marrow were fixed in $10 \%$ formalin for histopathological examination. In addition, the peripheral blood of animals was collected both prior to and 3, 7, 14, 21, 28, 36, 43 and 57 days after CAR-T administration. Total T cells [detected using anti-human CD3 (FITC) for recognizing T cells, Invitrogen, Cat. No: 2067138] and $\mathrm{CAR}^{+} \mathrm{T}$ cells [bio-antiFMC63, Invitrogen, Cat. No: 190507; APC streptavidin (BD Biosciences, Cat. No: 8326901)] were analyzed by flow cytometry (FACSCalibur, BD Biosciences). Anesthesia (by isoflurane inhalation), blood collection and necropsy were performed in a specific order (the untreated group, followed by the buffer group, T cell group, ssCART-19 $2 \times 10^{6}$ group, ssCART-19 $6 \times 10^{6}$ group, and ssCART-19 $20 \times 10^{6}$ group), to minimize potential confounders.

Various investigators were involved in the analysis of each animal. The only person aware of the treatment group allocation was the study director. Numbers were assigned to each sample and investigators conducting optical intensity examination, serum biochemical analysis, cytokine analysis, T/CAR-T cell analysis, and pathological examination were not aware of the animal's group/treatment.

\section{Statistical analysis}

All data are presented as the mean \pm standard deviation (SD) of $n$ values, where $n$ corresponds to the number of mice used. The Kaplan-Meier curves were plotted to estimate animal survival rates. Other statistical analyses were performed using one-way analysis of variance (ANOVA), followed by Dunnett's test for comparisons to the untreated or buffer groups. Figures were generated using GraphPad Prism 5 for Windows (GraphPad Software, San Diego, CA, USA). Statistical significance was determined using SPSS (ver.12), with $\mathrm{P}<0.05$ considered significantly different.

\section{Results}

\section{Biodistribution of ssCART-19 in NSG mice}

As shown in Figure 2, a single administration of ssCART-19 cells led to a wide distribution of ssCART-19 DNA in the 42 NSG mice. ssCART-19 DNA could be detected 3 hours 
A

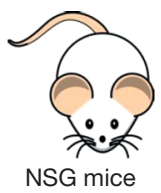

Raji-Luc xenografting

CART dosing

qPCR sampling

B

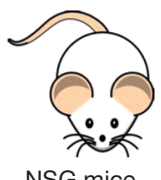

Raji-Luc xenografting

CART dosing

T/CAR ${ }^{+} T$ cells

Cytokine profile

Biochemical analysis

Pathological examination

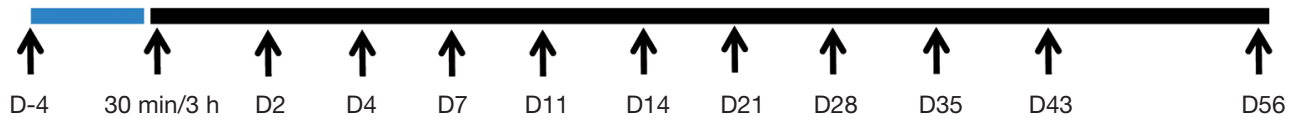

D56

Figure 1 Study schedule of biodistribution (A) and toxicity (B) studies. (A) On the day of CAR-T dosing, samples of different tissues were taken at 30 minutes and 3 hours after dosing for qPCR analysis. (B) Clinical symptoms were observed every day, while animal body weight and the fluorescence intensity were measured every week. Animals were anesthetized on 14 and 28 days post administration respectively for serum biochemical analysis, necropsy, and histopathological examination. The content of $\mathrm{T}$ cells and CAR ${ }^{+} \mathrm{T}$ cells were detected before

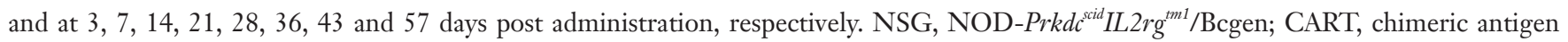
receptor T-cell; qPCR, quantitative real-time polymerase chain reaction; D, days before or after dosing; 30 min, 30 minutes after dosing; 3 h, 3 hours after dosing.

post administration in well-vascularized organs, such as the liver, spleen, lung, and bone marrow, suggesting that these tissues are primarily responsible for the distribution of ssCART-19 in mice. After 4 weeks, ssCART-19 DNA was detected in all tissues to varying degrees, indicating that ssCART-19 had been widely distributed in the body via the circulatory system. ssCART-19 DNA levels reached a peak in the uterus after 14 days, and in the epididymis and brain 4 weeks after the administration. The ssCART-19 DNA content peaked at 6 weeks post administration in peripheral blood, testis, kidney, liver, spleen, lung, heart, duodenum, colon, and fat and at 8 weeks post administration in the ovary, stomach, bone marrow and skeletal muscle. ssCART-19 cells were mainly distributed in the spleen, brain, fat, peripheral blood, skeletal muscle, epididymis, lung, uterus, liver, kidney, bone marrow and testis. The higher ssCART-19 content in fat may be related to the distribution via the reproductive system and digestive tract.

\section{Pharmacodynamics of regular CAR-T and ssCART-19}

The median survival times of animals administered RajiLuc alone, or together with $\mathrm{T}$ cells, regular CAR-T cells (at dosages of $1 \times 10^{6}, 3 \times 10^{6}$ and $6 \times 10^{6}$ ) and ssCART-19 cells (at dosages of $1 \times 10^{6}, 3 \times 10^{6}$ and $6 \times 10^{6}$ ) were $14,15,33,57$, 61, 24, 59 and 60 days, respectively. Regular CAR-T cells and ssCART-19 cells could significantly prolonged the median survival time of tumor-bearing mice $(\mathrm{P}<0.001)$. One male administered ssCART-19 survived for 90 days post administration.

The averaged fluorescence intensities of mice administered Raji-Luc are summarized in Figure 3. Fluorescence intensities 


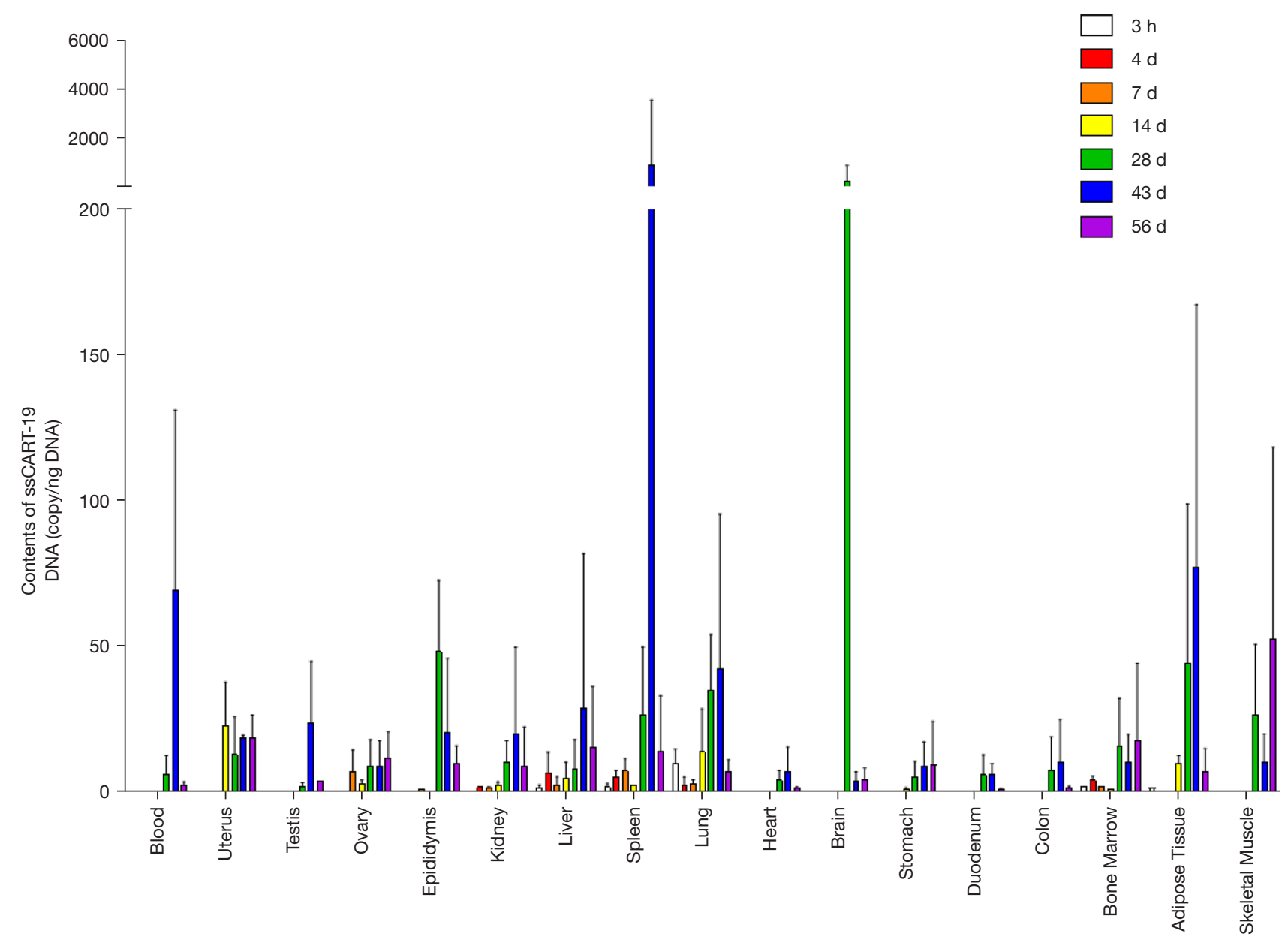

Figure 2 Biodistribution of ssCART-19 in NSG animals administrated with ssCART-19 ( $\mathrm{n}=6$ per group). The ssCART-19 DNA was widely distributed in the NSG mice after a single administration. ssCART-19 DNA could be detected 3 hours post administration in liver, spleen, lung, bone marrow, etc. The content of ssCART-19 DNA reached the peak in the uterus after 14 days, and in the epididymis and brain 4 weeks after the administration. The ssCART-19 DNA content in peripheral blood, testis, kidney, liver, spleen, lung, heart, duodenum, colon, and fat reached the peak value 6 weeks post administration, and it reached peak 8 weeks post administration in the ovary, stomach,

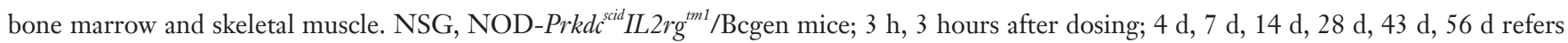
to 4 days, 7 days, 14 days, 28 days, 43 days, 56 days after dosing, respectively.

were significantly lower in animals administered regular CAR-T and ssCART-19 cells $\left(3 \times 10^{6}\right.$ and $6 \times 10^{6}$ per animal) than in animals administered buffer $(\mathrm{P}<0.05, \mathrm{P}<0.01)$ or $\mathrm{T}$ cells only $(\mathrm{P}<0.05)$. These differences began at day 1 post administration and exhibited a dose-response relationship.

Survival rates and pharmacodynamics must be analyzed in parallel; thus the samples listed in Table 1 were collected from animals dosed with Raji and vehicle/T cells/CAR-T cells without other intervention. The occurrence of lymphoma in multiple tissues and/or organs was confirmed by histopathological examination at the time of death.
Compared with lymphoma tumor-bearing mice, the incidence of lymphoma in animals administered regular CAR-T and ssCART-19 cells was evidently and dosedependently reduced as shown in Table 1 .

Histopathological and immunohistochemical examinations (CD3-positive $\mathrm{T}$ cells) were used to determine the tissue distribution of CAR-T cells in 36 animals in each group (regular CAR-T and ssCART-19, Table 2). The aggregation of CAR-T cells and immunerelated cells in multiple tissues and organs was mainly derived from the proliferation of regular CAR-T and 
A

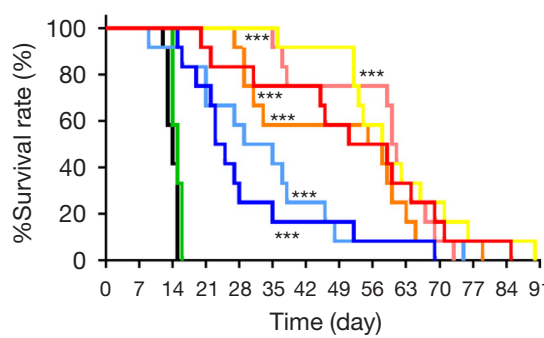

C

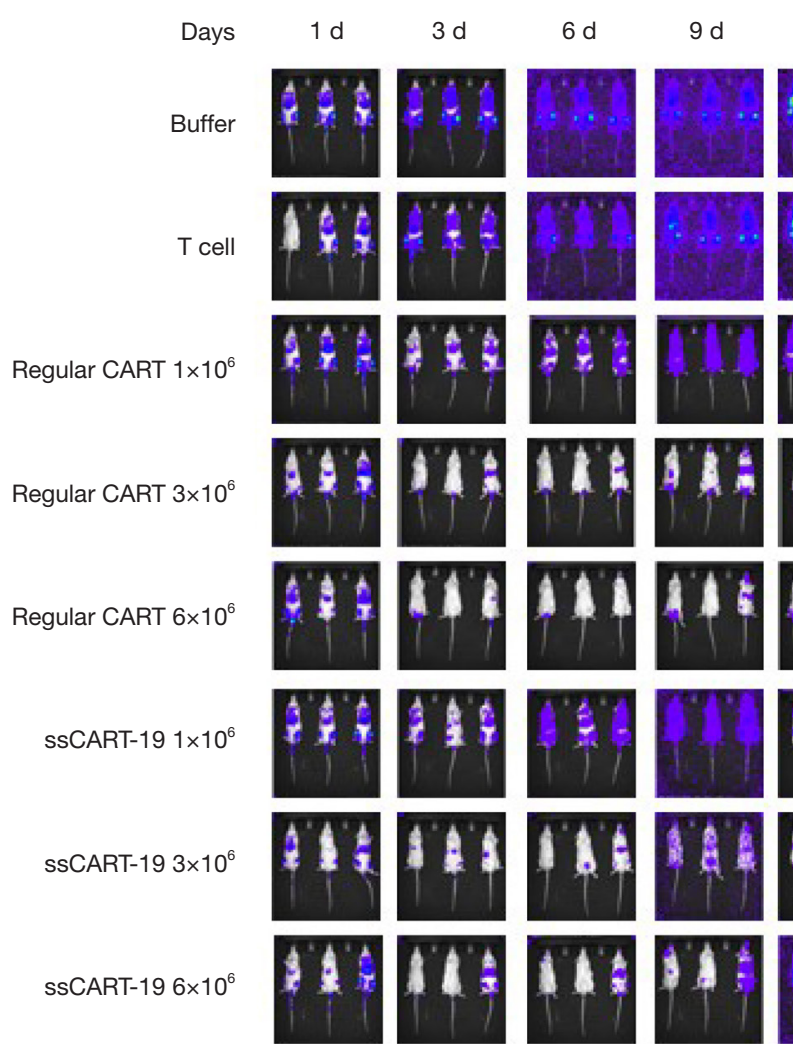

B
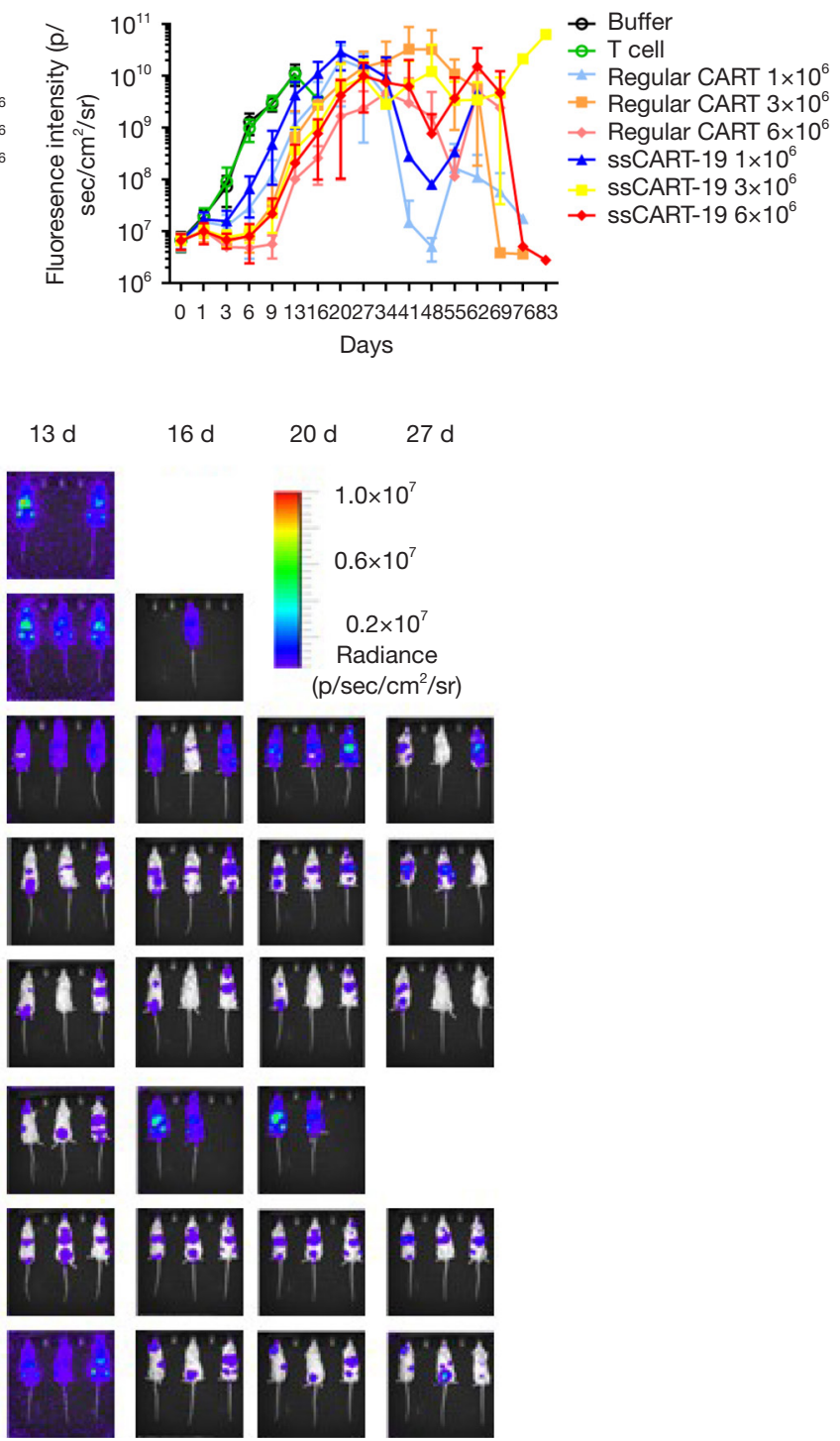
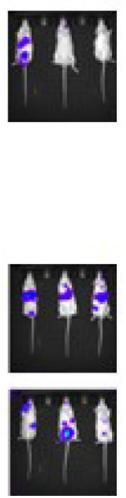

Figure 3 Effects of regular CAR-T and ssCART-19 to the survival rate and tumor clearance in NSG mice (n=6 per group). (A) Mean survival rate of animals bearing Raji-Luc cells were demonstrated and analyzed, as significant increases of survival rates can be found in all groups administrated with regular CAR-T and ssCART-19 comparing to the buffer group $(\mathrm{P}<0.001)$. (B) Summary of averaged fluorescence intensities of different groups. (C) In vivo fluorescence intensity of animals xenografted Raji-Luc cells were visualized and the mean fluorescence intensities in animals administrated with regular CAR-T and ssCART-19 were markedly lower than buffer group since 3 days after administration. 1 d, 3 d, 6 d, 9 d, 13 d, 16 d, 20 d, 27 d refers to 1 day, 3 days, 6 days, 9 days, 13 days, 16 days, 20 days, 27 days after dosing, respectively. ${ }^{* * *}$, indicates $\mathrm{P}<0.001$, comparing to the buffer group (Kaplan-Meier analysis). NSG, NOD-Prkd ${ }^{s i d} I L 2 r g^{t m 1} / B c g e n$ mice; CART, chimeric antigen receptor T-cell.

ssCART-19 cells and the activation of various immunerelated, pharmacodynamically active cells (mainly monocyte- macrophages and granulocytes). CAR-T cells can enter the brain through the blood-brain barrier and cause inflammation. The results of this study, suggested that the inflammatory responses were similar in animals dosed with regular CAR-T cells and ssCART-19 cells. Although there was mixed cell aggregation in the brain, the CAR-T 
Table 1 Incidence of lymphoma in multi-tissue and organs

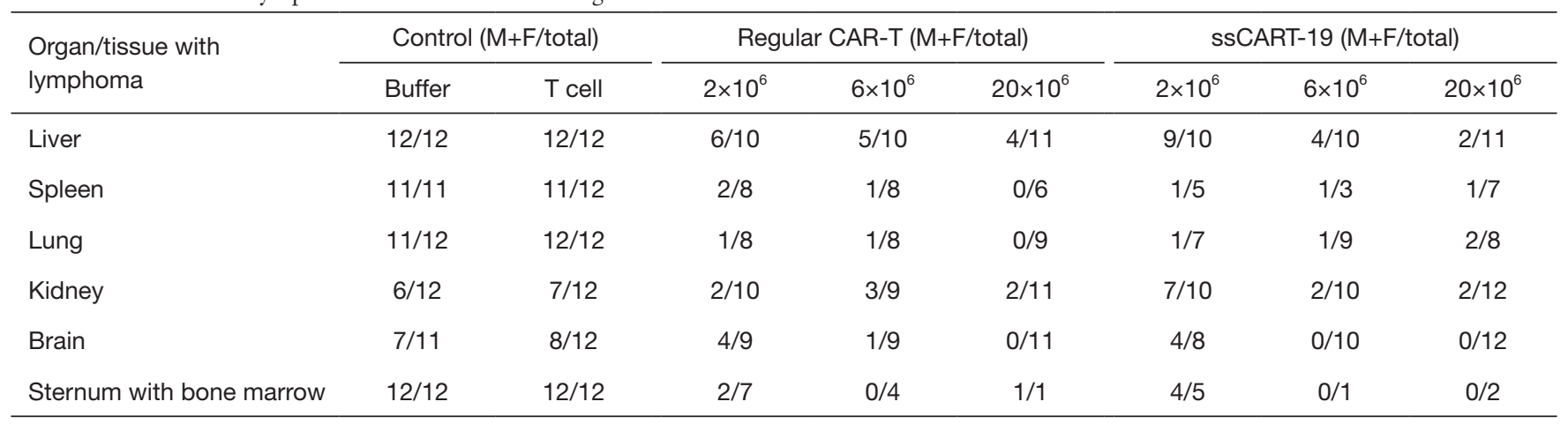

$\mathrm{M}+\mathrm{F} /$ total, number of male and female animals with lymphoma in this tissue/total number of animals examined in this group (tissue autolysis without histopathological examination). Buffer, T cell, indicate the animals dosed with buffer, T cells respectively; $2 \times 10^{6}, 2 \times 10^{6}$, and $2 \times 10^{6}$, the doses of regular CAR-T or SsCART-19 administered to the animals, respectively.

Table 2 Microscopic findings following the administration of regular CAR-T and ssCART-19 in NSG mice

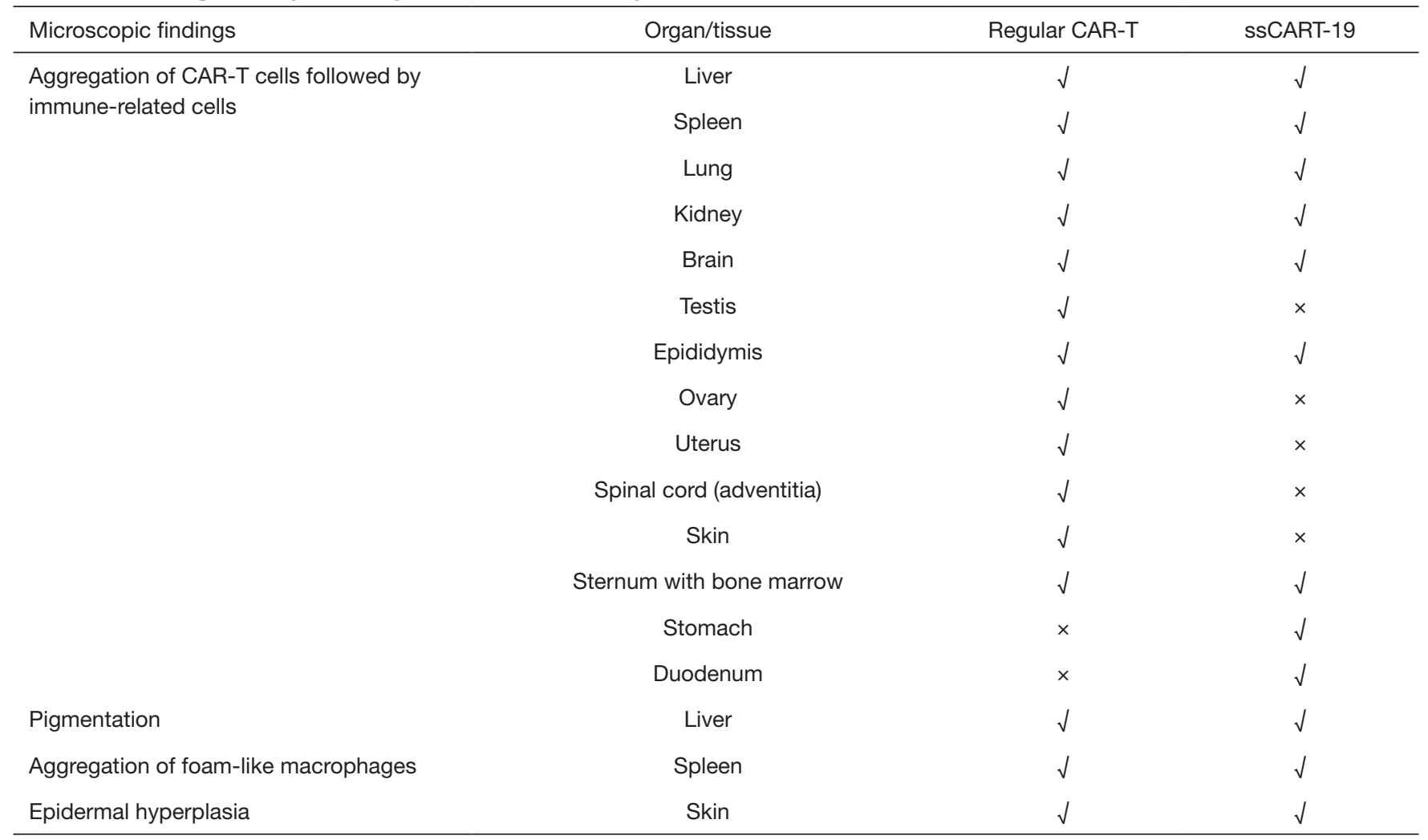

$\sqrt{ }$, indicates there was the microscopic finding(s) in the tissue/organ; $\times$, indicates there was no this microscopic finding in the tissue/organ; regular CAR-T, findings in animals administered regular CAR-T cells; SsCART-19, findings in animals administered ssCART-19 cells.

cell content at the time of the animal's death of the animal was likely not high enough to activate a strong cytokine storm response. However, our group compared the ability of regular CAR-T and ssCART-19 cells to inhibiting IL-6 release in both in vitro and in vivo systems (11), and revealed that the IL-6 levels were significantly lower in tumorbearing mice dosed with ssCART-19 cells than those dosed with regular CAR-T cells. 
Table 3 Percentage survival rate of each group at different time points (\%) ( $\mathrm{n}=24$ per group)

\begin{tabular}{|c|c|c|c|c|c|c|c|c|c|c|c|c|c|c|c|c|c|}
\hline Group & \multicolumn{17}{|c|}{ Percentage survival rate on different days post administration, days (\%) } \\
\hline Untreated group & 100 & 100 & 100 & 96 & 96 & 88 & 58 & 58 & 50 & 50 & 50 & 50 & 50 & 50 & 50 & 50 & 50 \\
\hline T cell group & 100 & 96 & 83 & 79 & 71 & 54 & 38 & 29 & 21 & 8 & 4 & 0 & 0 & 0 & 0 & 0 & 0 \\
\hline $\begin{array}{l}\text { ssCART-19, } \\
2 \times 10^{6} \text { group }\end{array}$ & 96 & 92 & 50 & 33 & 17 & 8 & 8 & 4 & 4 & 0 & 0 & 0 & 0 & 0 & 0 & 0 & 0 \\
\hline $\begin{array}{l}\text { ssCART-19, } \\
20 \times 10^{6} \text { group }\end{array}$ & 100 & 100 & 96 & 92 & 75 & 54 & 42 & 29 & 17 & 13 & 8 & 8 & 4 & 4 & 4 & 4 & 0 \\
\hline
\end{tabular}

In addition, GvHD related skin epidermal hyperplasia was observed in animals administered $6 \times 10^{6}$ regular CAR-T cells ( 3 in 9 animals) and $6 \times 10^{6}$ ssCART-19 cells ( 1 in 6 animals). The incidence of epidermal hyperplasia in animals administered ssCART-19 cells was slightly lower than in animals administered regular CAR-T cells.

\section{General toxicity}

In the toxicity study, the median survival times of animals administered buffer alone, Raji-Luc with $\mathrm{T}$ cells, and RajiLuc with ssCART-19 cells (at dosages of $2 \times 10^{6}, 6 \times 10^{6}$ and $20 \times 10^{6}$ ) were $89,44,22,37$, and 44 days, respectively. For the animals administered Raji-Luc only, $47 \%$ died before the first scheduled necropsy day (14 days post administration). In line with the pharmacodynamic data, ssCART-19 prolonged the median survival time of tumorbearing mice $(\mathrm{P}<0.001)$ in a dose-dependent manner, and four animals administered $20 \times 10^{6}$ of ssCART-19 cells survived over 112 days post administration (Table 3).

Abnormal clinical symptoms were observed in the tumor-bearing animals, including roachback, piloerection, hind limb paralysis, reduced activity and abdominal swelling (possibly related to the ascites or flatulence caused by the compression of the tumor in the abdominal cavity), which were attributed to the receipt of Raji-Luc cells. As demonstrated in Table 4, ssCART-19 reduced the incidence of piloerection and hind limb paralysis in a dose-dependent manner, thus the ssCART-19 was able to improve the clinical symptoms triggered by the proliferation of Raji-Luc cells in vivo.

In addition, both clinical observation and histopathological examination results indicated that there was no non-
Raji-Luc tumor formation, in the animals administered ssCART-19.

In the $2^{\text {nd }}$ week post administration, the average body weights of males administered different doses of ssCART-19 were significantly higher than those of the buffer group and $\mathrm{T}$ cell group $(\mathrm{P}<0.01)$, and there was a slight dose correlation (Figure 4). From the $3^{\text {rd }}$ to the $8^{\text {th }}$ week post administration, there was no significant difference in the averaged body weights of animals administered ssCART-19 compared with the untreated group. We believe that ssCART-19 may somewhat slow Raji-Luc cell proliferationinduced weight loss.

\section{T cell and $\mathrm{CAR}^{+} T$ cell determination}

In this study, we detected $\mathrm{T}$ lymphocytes originating from both the injected ssCART-19 and exogenous T cells, with changes in their relative levels due to proliferation and differentiation in the mice. Beginning on the $3^{\text {rd }}$ day post administration, both $\mathrm{T}$ cells and $\mathrm{CAR}^{+} \mathrm{T}$ cells were detected in animals dosed with ssCART-19 (Figure 5).

The number of $\mathrm{T}$ cells in the $\mathrm{T}$ cell group increased predominantly between the $14^{\text {th }}$ and $57^{\text {th }}$ days post administration, reaching a peak on the $21^{\text {st }}$ day post administration. In the ssCART-19 group, total $\mathrm{T}$ cells and CAR ${ }^{+} T$ cell levels increased markedly between $21^{\text {st }}$ and $43^{\text {rd }}$ days post administration. The magnitude of the increase was inversely proportional to the CAR-T dose, and the longest time to peak was observed in animals receiving the highest dose. We also observed that the distribution of $\mathrm{T}$ cells in the peripheral blood was positively correlated with the administered dose up to the $21^{\text {st }}$ day post administration; after the $21^{\text {st }}$ day, the proliferation of ssCART-19 cells in the 
Table 4 Summary of clinical symptoms

\begin{tabular}{|c|c|c|c|c|c|c|}
\hline Group & $\begin{array}{l}\text { Number of } \\
\text { animals }\end{array}$ & \multicolumn{5}{|c|}{ Number of animals with abnormal symptoms } \\
\hline Buffer group & 36 & 34 & 34 & 31 & 31 & 1 \\
\hline T cell group & 60 & 23 & 24 & 5 & 10 & 1 \\
\hline $\begin{array}{l}\text { ssCART-19, } 2 \times 10^{6} \\
\text { group }\end{array}$ & 60 & 17 & 22 & 2 & 7 & 16 \\
\hline $\begin{array}{l}\text { ssCART-19, } 20 \times 10^{6} \\
\text { group }\end{array}$ & 60 & 17 & 17 & 0 & 11 & 2 \\
\hline
\end{tabular}
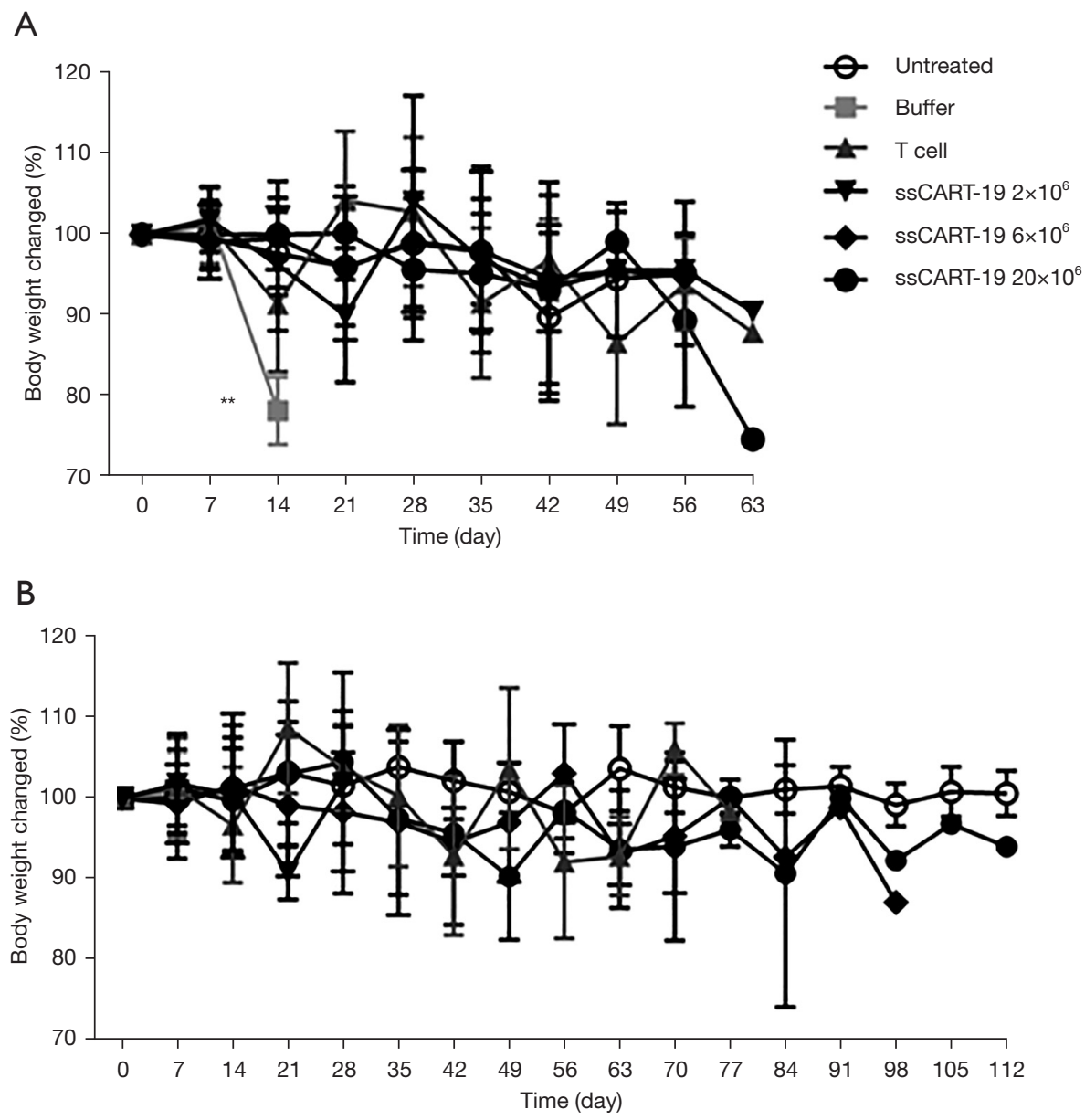

Figure 4 Changes on body weights in NSG mice over 113 days after administrated with ssCART-19 ( $\mathrm{n}=24$ for untreated group, $\mathrm{n}=18$ for buffer group, n=30 for the rest groups). Changes of male (A) and female (B) NSG mice body weights in different groups were demonstrated, and those administrated with ssCART-19 demonstrated a less body weight loss or slower body weight loss rate than the buffer group ( $\mathrm{P}<0.01)$. **, $\mathrm{P}<0.01$, comparing to the buffer group (one-way ANOVA). NSG, NOD-Prkdi $e^{\text {sid }} I L 2 r g^{\text {tm } 1} /$ Bcgen mice; ANOVA, analysis of variance. 

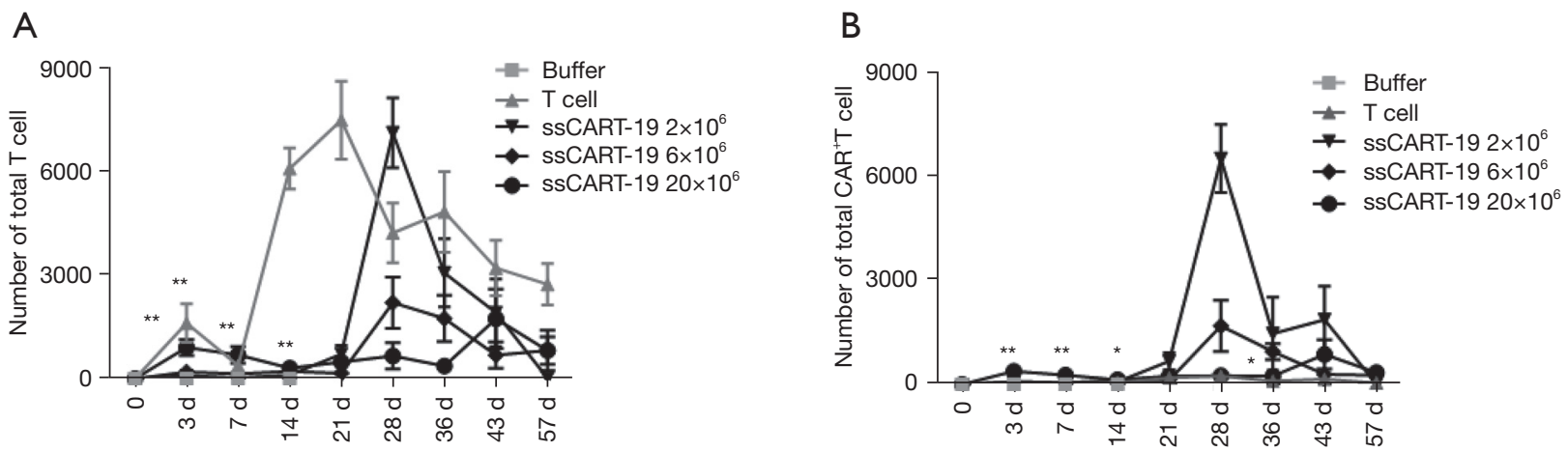

Figure 5 Proliferation of lymphocytes with $\mathrm{T}$ cells and CAR+T cells in animals administrated with ssCART-19 ( $\mathrm{n}=6$ per group). The amounts of $T$ cells in the $T$ cell group increased predominantly from $14^{\text {th }}$ to $57^{\text {th }}$ day post administration, and reached the peak on the $21^{\text {st }}$ day post administration $(\mathrm{P}<0.01)$. For the animals dosed with ssCART-19, both the amounts of total $\mathrm{T}$ cells and CAR ${ }^{+} \mathrm{T}$ cells increased markedly from $21^{\text {st }}$ to $43^{\text {rd }}$ days post administration $(\mathrm{P}<0.05, \mathrm{P}<0.01)$, and the increased amounts are inversely proportional to the doses, and the sample from animals with highest dose showed a longest time to peak. $3 \mathrm{~d}, 7 \mathrm{~d}, 14 \mathrm{~d}, 21 \mathrm{~d}, 28 \mathrm{~d}, 36 \mathrm{~d}, 43 \mathrm{~d}, 57 \mathrm{~d}$ refers to 3 days, 7 days, 14 days, 21 days, 28 days, 36 days, 43 days, 57 days after dosing, respectively. ${ }^{*}, \mathrm{P}<0.05$; ${ }^{*}, \mathrm{P}<0.01$, comparing to the buffer group (one-way ANOVA). ANOVA, analysis of variance.

peripheral blood was negatively correlated with dose. These findings may be associated with the degree of immune stimulation or immune memory of Raji-Luc cells, or the consumption of $\mathrm{T}$ cells and $\mathrm{CAR}^{+} \mathrm{T}$ cells in the animals that received higher doses.

\section{Effects of ssCART-19 to the human pro-inflammatory cytokine profile in mice}

As summarized in Figure 6, IL-10 was detected in all tumorbearing animals. On the $14^{\text {th }}$ day post administration, IL10 levels were lower in animals given T cells or ssCART-19 cells than in those of the buffer group $(\mathrm{P}<0.05, \mathrm{P}<0.01)$. A dose-response tendency was also observed: that is, as the dose of ssCART-19 cells increased, the level of IL-10 decreased. IL-10 levels are related to the activity of Raji-Luc tumor cells in tumor-bearing animals (15), therefore the decrease in IL-10 levels in animals in the ssCART-19 group may be associated with inhibition of tumor proliferation. However, IL-10 levels in animals given ssCART-19 cells were further increased 28 days after administration, suggesting the growth of Raji-Luc tumor cells in vivo.

IFN- $\gamma$ and IL-6 levels were increased in the animals given ssCART-19, indicating anti-tumor activity. IFN- $\gamma$ was first detected on the $14^{\text {th }}$ day post administration in animals given T cells or ssCART-19 cells: these levels were much higher in each group on the $28^{\text {th }}$ day post administration. IL-6 was detected in all groups on the $14^{\text {th }}$ day post administration. IL-6 levels were lower in animals given ssCART-19 $\left(2 \times 10^{6}\right.$ and $\left.6 \times 10^{6}\right)$ than in animals in the buffer group $(\mathrm{P}<0.05, \mathrm{P}<0.01)$ or the $\mathrm{T}$ cell group $(\mathrm{P}<0.05, \mathrm{P}<0.01)$. On the $28^{\text {th }}$ day post administration, animals given ssCART-19 exhibited decreased IL-6 levels that were inversely and dose-dependently related to the ssCART-19 dosage. Both CAR ${ }^{+}$T cell number and IL-6 levels were positively correlated with the proliferation of ssCART-19 cells in animals, in accordance with the findings of our previous study (11). Small amounts of TNF were also detected, though the dose-response correlation was not clear. In this study, the levels of IL-2 and IL-17A were positively and dose-dependently associated with the ssCART-19. IL-4 was only detected in a few animals dosed with $20 \times 10^{6}$ ssCART- 19 cells.

Together, these results suggested that ssCART-19 cells proliferated in vivo and exerted an appreciable tumorkilling effect. Our histopathological results did not reveal any evidence of an excessive immune response or cytokine storm related to the ssCART-19 administration.

\section{Clinical chemistry}

Clinical chemistry indices were analyzed at the $2^{\text {nd }}$ week and $4^{\text {th }}$ week post administration, as shown in Table 5 . At the $2^{\text {nd }}$ week post administration, the average ALT of the animals in the buffer group was significantly higher than that of the animals in the untreated group $(\mathrm{P}<0.01)$. Conversely, the 
A

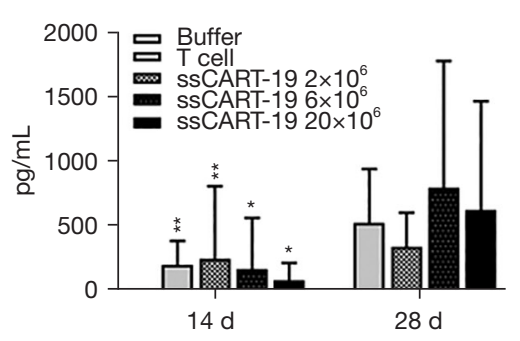

D

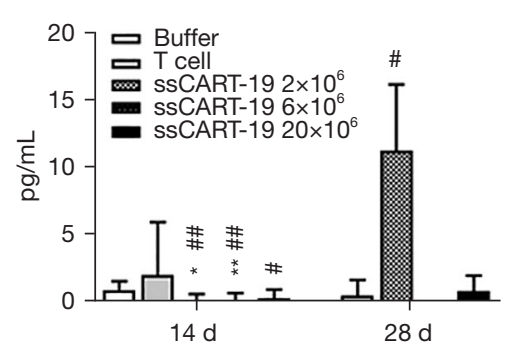

G

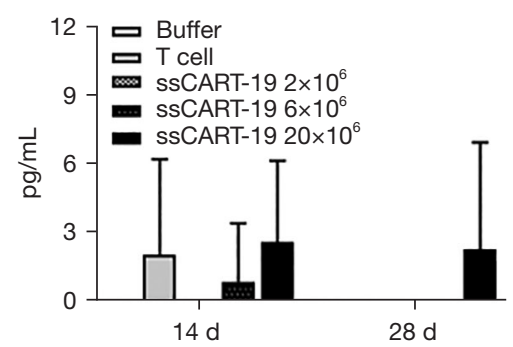

B

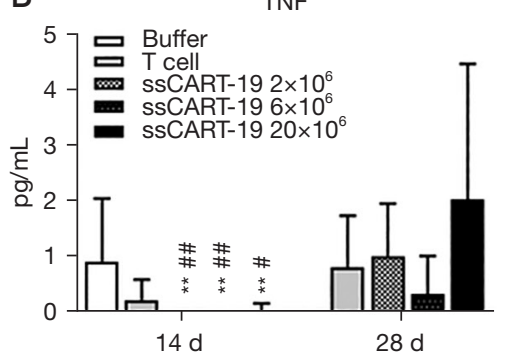

$\mathrm{E}$

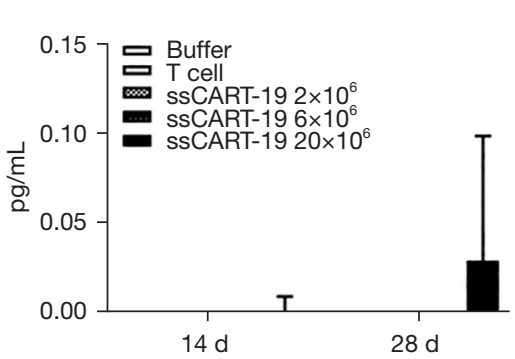

C

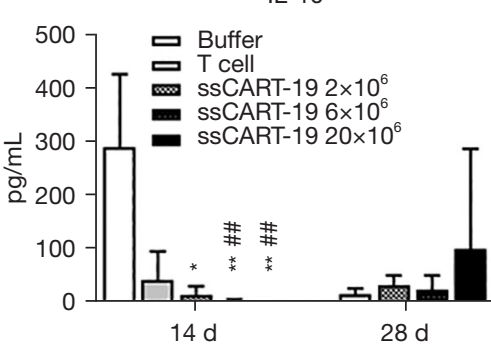

$\mathrm{F}$

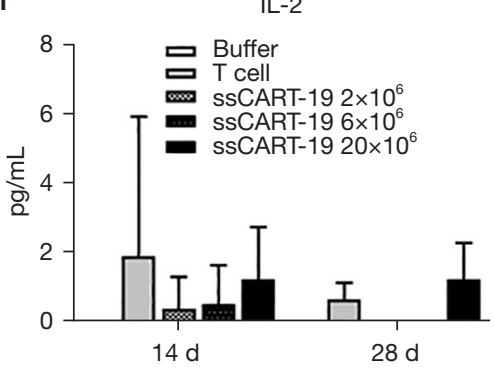

Figure 6 Human cytokine profiles in NSG mice ( $n=6$ for buffer group, $n=12$ for rest of the groups). The levels cytokines of IFN- $\gamma$ (A), TNF (B), IL-10 (C), IL-6 (D), IL-4 (E), IL-2 (F), and IL-17A (G) in animals of each group at 14 days or 28 days post administration are demonstrated. Levels of IL-10 in animals given T cells or ssCART-19 were lower than that of the buffer group $(\mathrm{P}<0.05, \mathrm{P}<0.01)$ on the $14^{\text {th }}$ day post administration. IL-10 levels in animals given ssCART-19 were further increased the 28 days after administration. The levels of IFN- $\gamma$ and IL- 6 were increased in the animals given ssCART-19. IFN- $\gamma$ was detected in animals given T cells and ssCART-19 on the $14^{\text {th }}$ day post administration, and the levels of IFN- $\gamma$ in each group were much higher on $28^{\text {th }}$ day post administration. IL- 6 was detected in all groups on $14^{\text {th }}$ day post administration, and the IL-6 levels of animals given ssCART- 19 at $2 \times 10^{6}$ and $6 \times 10^{6}$ were lower than that of the buffer group $\left({ }^{*}, \mathrm{P}<0.05 ;{ }^{* *}, \mathrm{P}<0.01\right)$ and the $\mathrm{T}$ cell group $\left(\stackrel{\#}{ }, \mathrm{P}<0.05 ;{ }^{* \#}, \mathrm{P}<0.01\right)$; on the $28^{\text {th }}$ day post administration, the levels of IL-6 in animals given ssCART-19 were decreased along with the dose increase of ssCART-19. $14 \mathrm{~d}, 28 \mathrm{~d}$ refers to 14 days, 28 days after dosing, respectively. NSG, NOD-Prkdc $c^{\text {sid }} I L 2 r g^{t m 1} / \mathrm{Bcgen}$ mice; IFN- $\gamma$, interferon-gamma; TNF, tumor necrosis factor; IL, interleukin.

average ALT of animals in the T cell or ssCART-19 groups was significantly lower than that of the animals in the buffer group $(\mathrm{P}<0.05, \mathrm{P}<0.01)$, suggesting that ssCART-19 could alleviate Raji-Luc-related liver toxicity. By the $4^{\text {th }}$ week post administration, the ALT of animals given $20 \times 10^{6}$ ssCART-19 $(91 \pm 49 \mathrm{U} / \mathrm{L})$ was significantly increased compared with that of the animals in the untreated group $(\mathrm{P}<0.05)$ but was still significantly lower than the ALT value of animals in buffer group $(343 \pm 280 \mathrm{U} / \mathrm{L})$ at the $2^{\text {nd }}$ week post administration. As suggested by the histopathological observations, this may be related to a weaker tumor suppressive effect at the $4^{\text {th }}$ week post administration than at the $2^{\text {nd }}$ week post administration. In the $2^{\text {nd }}$ week post administration, the average AST value of the buffer group was higher than that of the untreated group $(\mathrm{P}<0.01)$. Further, the AST value of the animals given ssCART-19 was significantly lower than 


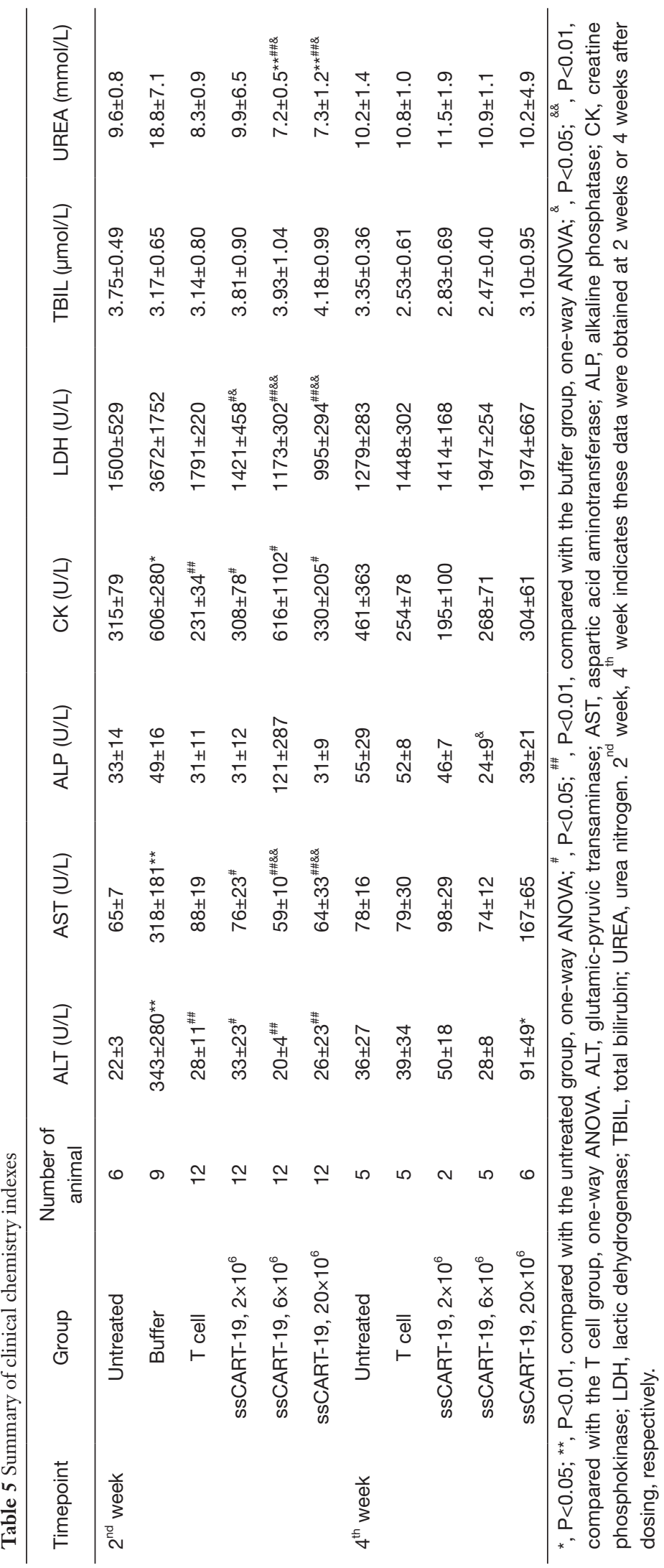


Table 6 Mixed cell aggregation associated with administration of T cells and ssCART-19

\begin{tabular}{|c|c|c|c|c|c|c|}
\hline Groups & \multicolumn{6}{|c|}{ Number of animals affected/number of animals examined } \\
\hline Number of animals & 12 & 24 & 24 & 24 & 24 & 24 \\
\hline Liver & $0 / 12$ & $0 / 11$ & $7 / 23$ & $6 / 23$ & $15 / 24$ & $10 / 24$ \\
\hline Kidney & $0 / 12$ & $0 / 11$ & $0 / 23$ & $0 / 23$ & $3 / 24$ & $1 / 24$ \\
\hline Spleen & $0 / 12$ & $0 / 11$ & $16 / 23$ & $15 / 23$ & $23 / 24$ & $22 / 24$ \\
\hline \multicolumn{7}{|l|}{4 weeks after administration } \\
\hline Number of animals & 12 & 12 & 12 & 12 & 12 & 12 \\
\hline Number of animals examined & 12 & 6 & 10 & 5 & 9 & 10 \\
\hline \multicolumn{7}{|l|}{ Tissues or organs } \\
\hline Liver & $0 / 12$ & $0 / 6$ & $10 / 10$ & $0 / 5$ & $2 / 9$ & $7 / 10$ \\
\hline Kidney & $0 / 12$ & $0 / 6$ & $7 / 10$ & $0 / 5$ & $0 / 9$ & $2 / 10$ \\
\hline Spleen & $0 / 12$ & $0 / 6$ & $10 / 10$ & $5 / 5$ & $7 / 9$ & $9 / 10$ \\
\hline
\end{tabular}

${ }^{*}$, only samples from females are included.

that of the buffer group or $\mathrm{T}$ cell groups $(\mathrm{P}<0.05, \mathrm{P}<0.01)$. Macroscopic observation of the livers of animals in the buffer group revealed white or gray spots/plaques in the liver caused by Raji-Luc. The formation of liver lymphoma was observed by microscopy. Therefore, the fluctuation of ALT in the ssCART-19 $20 \times 10^{6}$ group may be attributed to the formation of liver lymphoma, mixed cell aggregation, or the killing effects of ssCART-19 in vivo. In the buffer group, elevated ALT and AST at the $2^{\text {nd }}$ week were associated with liver tumor burden. However, the reduction in ALT and AST in animals given ssCART-19 suggests an inhibitory effect on Raji-Luc cell-induced hepatotoxicity. In addition, CK, LDH and UREA levels were significantly lower in animals administered ssCART-19 than in those in the buffer group $(\mathrm{P}<0.05, \mathrm{P}<0.01)$. The reductions in ALP, CK and UREA have no practical significance in toxicology.

\section{Histopathological changes}

Histopathological changes associated with the administration of ssCART-19 included mixed cell aggregation (Table 6, Figure 7) in the liver, spleen, lung, kidney, brain, sternum (bone marrow), ovary, uterus, and skin (abdomen). Mixed cell aggregation was attributed to the proliferation of ssCART-19 cells and various immune-related cells (mainly macrophages and neutrophils in T-cell-deficient NSG mice). The mixed cell aggregations found in various organs also reflected the pharmacodynamic action of ssCART-19. 

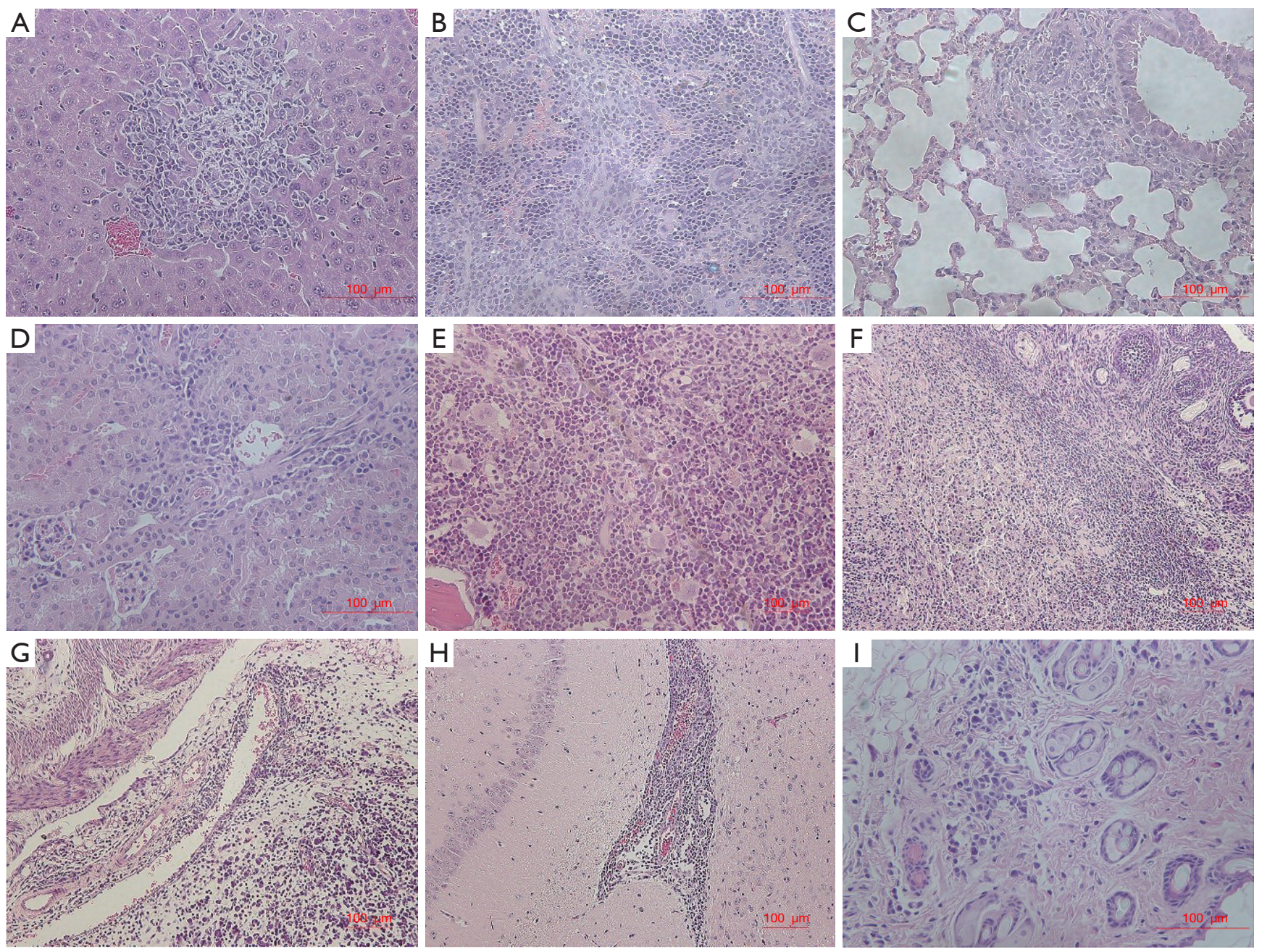

Figure 7 Histopathological changes associated with ssCART-19. The histopathological changes (hematoxylin and eosin stain) related to the administration of ssCART-19 was the mixed cell aggregation of multiple tissues and organs in NSG mice. Mixed cell aggregation was observed in liver $(A, \times 200)$, spleen $(B, \times 200)$, lung $(C, \times 100)$, kidney $(\mathrm{D}, \times 100)$, bone marrow $(\mathrm{E}, \times 100)$, ovary $(\mathrm{F}, \times 100)$ uterus $(\mathrm{G}, \times 100)$, brain $(\mathrm{H}, \times 100)$ and skin $(\mathrm{I}, \times 200)$ in animals administrated with ssCART-19. NSG, NOD-Prkd $c^{\text {scid }} I L 2 r g^{\text {tml }} /$ Bcgen mice.

\section{Discussion}

CAR-T therapy is highly effective against relapsed or refractory ALL, has brought hope for many cancer patients, and has become a hotspot of the research and development for ALL. However, challenges remain for the treatment of central nervous system relapse of ALL, which accounts for one third of ALL relapses and currently lack of potent and safe therapy (16). Major obstacles preventing the broad application of this immunotherapy include the unique treatment-related toxicities of (CRS and neurotoxicity) that occur in most patients (17). Most reports to date have considered CRS and neurotoxicity in aggregate for toxicity reporting, but it is increasingly appreciated that CRS and neurotoxicity may occur separately with distinct timings and responses to intervention (18). It has been suggested that targeted interventions, such as IL-6 receptor blockade, could be effective therapies for CRS and severe CART-related encephalopathy (sCRES) (19), which display a significant physiological overlap. Both CRS and sCRES are associated with the instant eruption of the proinflammatory cytokines, especially IL-6, following the activation of immune cascades by CAR-T cells (20). Monocytic release of IL-6 is considered the primary mechanism underlying CRS during CAR T cell therapy. Giavridis et al. (21), 
demonstrated that colocalized myeloid cells could be the main source of macrophage-associated IL-6 in mice infused with CAR-T cells. As reported previously, our group has produced an anti-CD19 CAR-T cell (ssCART-19) with short hairpin RNA (shRNA)-mediated IL-6 knockdown (12) to treat central nervous system relapse of ALL without the life-threatening CRS and the CRES (12). We have previously demonstrated that serum IL-6 levels in the tumor-bearing animals treated with ssCART-19 lower than those in animals treated with regular CAR-T cells (11). Our data revealed that $\mathrm{CAR}^{+} \mathrm{T}$ cells were detected in the peripheral blood beginning at 3 days following the administration of ssCART-19 and that the number of $\mathrm{CAR}^{+} \mathrm{T}$ cells in the peripheral blood samples increased significantly and reached a peak approximately 3 weeks post administration. ssCART-19 induced an increase in IFN- $\gamma$, TNF, IL-2, and IL-17A levels and a decrease in IL10 and IL-6 levels, indicating that it proliferated in animals and demonstrated an appreciable tumor-killing effect. There was a positive correlation between the IL-6 levels and the number of $\mathrm{T}$ cells and ssCART-19 cells in animals. We have previously reported that CART-19-derived IL-6 triggers IL- 6 release by monocytes and that ssCART-19 cells markedly reduce the release of IL-6 from monocytes in vitro (11). Additionally, IL-6 levels were significantly lower in tumor-bearing mice dosed with ssCART-19 than in those dosed with regular CAR-T cells (11). In this study, we reproduced these results and showed a dose-response effect. The clinical efficacy of the ssCART-19 in eliminating ALLrelated symptoms and leukemic blasts in the cerebrospinal fluid of patients has been demonstrated in a few clinical cases $(12,13)$. Due to the limited blood samples collected from mice, the levels of mouse-derived cytokines were not included in this study. In the future, analysis of this type data might also provide helpful information for understanding the immune response of the animals administered the CAR-T cells.

As revealed by Singh et al, blockade of IL-6 has no impact on the proliferation and antitumor efficacy of CAR-T cells (22), and our data further confirmed this hypothesis for ssCART-19 cells in vivo. In the pharmacodynamic study, regular CAR-T or ssCART-19 cells were intravenously injected into the tumor-bearing NSG mice, The doses used, while administered in a single injection, were equivalent to 1,3 and 6 times the dose intended to be used in patients. Our data demonstrated that both regular CAR-T cells and ssCART-19 cells could significantly prolong the survival time of tumor-bearing mice, and could somewhat slow down the weight loss caused by Raji-Luc cells. They could also effectively alleviate the clinical manifestations caused by Raji-Luc cell load and significantly reduce both the fluorescence intensity of Raji-luc cells in vivo, and the incidence of lymphomas in various tissues and organs in tumor-bearing animals. GvHD, a donor T-cellmediated disorder, usually manifests as damage to the skin, gastrointestinal tract, lungs, and liver in $70 \%$ of patients receiving the hematopoietic cell transplantation (23). In this study, the frequencies of GvHD-related clinical symptoms, such as roachback, piloerection, and reduced activity were not increased in the animals given ssCART-19 compared to those in the buffer group, and no GvHDrelated histopathological changes were observed in tissues from ssCART-19-treated animals. The incidence of GvHD reaction caused by ssCART-19 cells was slightly lower than that caused by regular CAR-T cells.

The purpose of biodistribution studies is to determine the organs/tissues where the ssCART-19 may be distributed following a pharmacodynamically-relevant dose. Due to the small number of animals assessed at each time point and the individual variations in animals, the error bars at some time points were high. This is now recognized as an indispensable parts of the effectiveness and safety evaluation of CAR-T cells (24). As demonstrated, ssCART-19 cells were mainly accumulated in the liver, spleen, lung, bone marrow and other well-vascularized organs within 3 hours, and were widely distributed via the circulatory system to most organs/tissues within 4 weeks of administration. Organs/tissues, such as spleen, brain, fat, peripheral blood, skeletal muscle, epididymis, lung, uterus, liver, kidney, bone marrow, and testis, displayed a higher ssCART-19 content than other organs/tissues. These are consistent with previous reports $(25,26)$. The spleen is an important immune organ, and the accumulation of CAR-T cells in the spleen may also be associated with target recognition (26).

Few case reports have described the clinical application of ssCART-19 $(12,13)$. The proposed clinical dose of ssCART-19 was estimated based on the existing clinical data, and calculated to be $1 \times 10^{6}$ per animal in mice. To investigate the possible toxicity of ssCART-19, tumorbearing NSG mice were administered a single intravenous dose of $2 \times 10^{6}, 6 \times 10^{6}$, and $20 \times 10^{6}$ ssCART-19 cells per animal, which is approximately 2 times, 6 times and 20 times the estimated clinical dose. Our data clearly demonstrated that ssCART-19 can effectively inhibit the 
proliferation of Raji-Luc cells in tumor-bearing NSG mice and reduce the incidence of lymphomas in the liver, kidneys, spleen, lungs, brain, bone marrow, testis and ovary. Further, the survival rate was noticeably improved within 2 weeks of administration. In the animals administered ssCART-19, the clinical symptoms and weight loss caused by tumor cell proliferation were alleviated. Histopathologically, administration of ssCART-19 caused multi-tissue/organ mixed cell aggregation (mainly monocytes, macrophages and granulocytes) and no histopathological changes related to GvHD. In addition, no Raji-Luc-mediated tumor formation was observed in the animals given ssCART-19. Though CAR-T-associated neurotoxicity has been welldescribed in human patients (25), severe neurotoxicity symptoms related to ssCART-19 administration were not observed in the animals in our study. CAR-T cells are able to enter the brain tissue through the blood-brain barrier and cause meningitis, which is histopathologically diagnosed as the aggregation of CAR-T cells followed by immune-related cells (27). CAR-T cells can target tumors in the central nervous system and prevent the neurological complications induced by ALL (28). As shown in a recent study, both CAR and non-CAR T cell infiltration was observed in the CSF and brain parenchyma of non-human primates with encephalitis after the administration of CAR-T cells (29). However, the role of T cells as bystanders or active players in the development and maintenance of neurotoxicity symptoms remains to be investigated. In this study, ssCART-19 was found in the brains of animals but did not appear to exert significant toxicity effects in the central nervous system.

\section{Conclusions}

In summary, our study revealed that ssCART-19 with IL-6 knockdown decreased the secretion of IL-6 without affecting anti-tumor activity. Our results demonstrated the clinical advantages of this approach for patients with central nervous system leukemia. The efficacy of ssCART-19 for the treatment of lymphoma as well as their toxicity potential were comprehensively evaluated in this study. Our data also suggested that ssCART-19 can prolong the survival time of tumor-bearing mice without the associated risks of immunotoxicity and tumorigenicity. These data were used to support an investigational new drug (IND) application for ssCART-19 to the National Medical Products Administration of China, and in 2020 ssCART-19 was given authorization for use in clinical trials.

\section{Acknowledgments}

The authors would like to thank Chao Wang, Ming Li, Chao Qin, Jing Zhao, Hua Jiang, Yufa Miao, and Yanwei Yang at National Center for Safety Evaluation of Drugs, as well as Ailing Wang at Beijing Huatai Biotechnology Co., Ltd., for their expert technical assistance provided.

Funding: This work was supported by the 'Significant New Drugs Development' (No. 2018ZX09201017-001), 'National Key Research and Development Program' (No. 2016YFA0101503) and the 'Chinese Academy of Sciences Strategic Leading Science and Technology Project' (No. XDA16040502) from the Ministry of Science and Technology of the People's Republic of China (http://www. most.gov.cn/). The funders have neither part nor lot in the design, analysis and reporting of the study.

\section{Footnote}

Reporting Checklist: The authors have completed the ARRIVE reporting checklist. Available at https://dx.doi. org/10.21037/atm-21-3372

Data Sharing Statement: Available at https://dx.doi. org/10.21037/atm-21-3372

Conflicts of Interest: All authors have completed the ICMJE uniform disclosure form (available at https:// dx.doi.org/10.21037/atm-21-3372). HW, GH, TH, ZQ, MW, YH receive the following fundings: 'Significant New Drugs Development' (No. 2018ZX09201017-001) from the Ministry of Science and Technology of China; 'National Key Research and Development Program' (No. 2016YFA0101503) from the Ministry of Science and Technology of China; 'Chinese Academy of Sciences Strategic Leading Science and Technology Project' (No. XDA16040502) from the Ministry of Science and Technology of China. JS is a full-time employee at Shanghai Unicar Biomed-Pharmaceutical Technology Co. Ltd. from 2018-2021, during the conduct of the study. ZY, LK, XL, LY are full-time employees at Shanghai Unicar BiomedPharmaceutical Technology Co. Ltd. from 2015-2021, during the conduct of the study. The authors have no other conflicts of interest to declare.

Ethical Statement: The authors are accountable for all aspects of the work in ensuring that questions related to the accuracy or integrity of any part of the work 
are appropriately investigated and resolved. All animal experimental procedures were approved by the Institutional Animal Care and Use Committee (IACUC) of the National Center for Safety Evaluation of Drugs (NCSED, IACUC approval No. IACUC-2019-033, IACUC-2019-035, IACUC-2019-050), in compliance with the IACUC Constitution of NCSED, the Guide for the Care and Use of Laboratory Animals (https://grants.nih.gov/grants/olaw/ Guide-for-the-Care-and-use-of-laboratory-animals.pdf) and AAALAC International's Position Statement. The animals were anaesthetized with isoflurane before blood sampling or necropsy. Adverse events that could be found in this study including loss of body weight, roachback, piloerection, hind limb paralysis, which are associated with the xenografting of Raji cells. All study protocols (including the research question, key design features, and analysis plan) were prepared before the study and archived at National Center for Safety Evaluation of Drugs.

Open Access Statement: This is an Open Access article distributed in accordance with the Creative Commons Attribution-NonCommercial-NoDerivs 4.0 International License (CC BY-NC-ND 4.0), which permits the noncommercial replication and distribution of the article with the strict proviso that no changes or edits are made and the original work is properly cited (including links to both the formal publication through the relevant DOI and the license). See: https://creativecommons.org/licenses/by-nc-nd/4.0/.

\section{References}

1. Wang Z, Wu Z, Liu Y, et al. New development in CAR-T cell therapy. J Hematol Oncol 2017;10:53.

2. Maude SL, Frey N, Shaw PA, et al. Chimeric antigen receptor $\mathrm{T}$ cells for sustained remissions in leukemia. $\mathrm{N}$ Engl J Med 2014;371:1507-17.

3. Porter DL, Hwang WT, Frey NV, et al. Chimeric antigen receptor $\mathrm{T}$ cells persist and induce sustained remissions in relapsed refractory chronic lymphocytic leukemia. Sci Transl Med 2015;7:303ra139.

4. Ruella M, Kenderian SS. Next-Generation Chimeric Antigen Receptor T-Cell Therapy: Going off the Shelf. BioDrugs 2017;31:473-81.

5. Neelapu SS, Locke FL, Bartlett NL, et al. Axicabtagene Ciloleucel CAR T-Cell Therapy in Refractory Large B-Cell Lymphoma. N Engl J Med 2017;377:2531-44.

6. Oved JH, Barrett DM, Teachey DT. Cellular therapy: Immune-related complications. Immunol Rev
2019;290:114-26.

7. Brudno JN, Kochenderfer JN. Toxicities of chimeric antigen receptor $\mathrm{T}$ cells: recognition and management. Blood 2016;127:3321-30.

8. Grupp SA, Kalos M, Barrett D, et al. Chimeric antigen receptor-modified $\mathrm{T}$ cells for acute lymphoid leukemia. $\mathrm{N}$ Engl J Med 2013;368:1509-18.

9. Gofshteyn JS, Shaw PA, Teachey DT, et al. Neurotoxicity after CTL019 in a pediatric and young adult cohort. Ann Neurol 2018;84:537-46.

10. Davila ML, Riviere I, Wang X, et al. Efficacy and toxicity management of $19-28 z$ CAR T cell therapy in B cell acute lymphoblastic leukemia. Sci Transl Med 2014;6:224ra25.

11. Kang L, Tang X, Zhang J, et al. Interleukin-6-knockdown of chimeric antigen receptor-modified $\mathrm{T}$ cells significantly reduces IL-6 release from monocytes. Exp Hematol Oncol 2020;9:11.

12. Liu ZF, Chen LY, Wang J, et al. Successful treatment of acute B lymphoblastic leukemia relapse in the skin and testicle by anti-CD19 CAR-T with IL-6 knocking down: a case report. Biomark Res 2020;8:12.

13. Chen LY, Kang LQ, Zhou HX, et al. Successful application of anti-CD19 CAR-T therapy with IL-6 knocking down to patients with central nervous system B-cell acute lymphocytic leukemia. Transl Oncol 2020;13:100838.

14. Chu Y, Hochberg J, Yahr A, et al. Targeting CD20+ Aggressive B-cell Non-Hodgkin Lymphoma by AntiCD20 CAR mRNA-Modified Expanded Natural Killer Cells In Vitro and in NSG Mice. Cancer Immunol Res 2015;3:333-44.

15. Wen H, Qu Z, Yan Y, et al. Preclinical safety evaluation of chimeric antigen receptor-modified $T$ cells against $C D 19$ in NSG mice. Ann Transl Med 2019;7:735.

16. Krishnan S, Wade R, Moorman AV, et al. Temporal changes in the incidence and pattern of central nervous system relapses in children with acute lymphoblastic leukaemia treated on four consecutive Medical Research Council trials, 1985-2001. Leukemia 2010;24:450-9.

17. Acharya UH, Dhawale T, Yun S, et al. Management of cytokine release syndrome and neurotoxicity in chimeric antigen receptor (CAR) T cell therapy. Expert Rev Hematol 2019;12:195-205.

18. Santomasso BD, Park JH, Salloum D, et al. Clinical and Biological Correlates of Neurotoxicity Associated with CAR T-cell Therapy in Patients with B-cell Acute Lymphoblastic Leukemia. Cancer Discov 2018;8:958-71.

19. Mackall CL, Miklos DB. CNS Endothelial Cell Activation Emerges as a Driver of CAR T Cell-Associated 
Neurotoxicity. Cancer Discov 2017;7:1371-3.

20. Rubin DB, Danish HH, Ali AB, et al. Neurological toxicities associated with chimeric antigen receptor T-cell therapy. Brain 2019;142:1334-48.

21. Giavridis T, van der Stegen SJC, Eyquem J, et al. CAR $\mathrm{T}$ cell-induced cytokine release syndrome is mediated by macrophages and abated by IL-1 blockade. Nat Med 2018;24:731-8.

22. Singh N, Hofmann TJ, Gershenson Z, et al. Monocyte lineage-derived IL-6 does not affect chimeric antigen receptor T-cell function. Cytotherapy 2017;19:867-80.

23. Salomao M, Dorritie K, Mapara MY, et al. Histopathology of Graft-vs-Host Disease of Gastrointestinal Tract and Liver: An Update. Am J Clin Pathol 2016;145:591-603.

24. Ying Z, He T, Wang X, et al. Distribution of chimeric antigen receptor-modified T cells against CD19 in B-cell

Cite this article as: Wen H, Huo G, Hou T, Qu Z, Sun J, Yu Z, Kang L, Wang M, Lou X, Yu L, Huo Y. Preclinical efficacy and safety evaluation of interleukin-6-knockdown CAR-T cells targeting at CD19. Ann Transl Med 2021;9(23):1713. doi: 10.21037/atm-21-3372 malignancies. BMC Cancer 2021;21:198.

25. Hunter BD, Jacobson CA. CAR T-Cell Associated Neurotoxicity: Mechanisms, Clinicopathologic Correlates, and Future Directions. J Natl Cancer Inst 2019;111:646-54.

26. Lewis SM, Williams A, Eisenbarth SC. Structure and function of the immune system in the spleen. Sci Immunol 2019;4:eaau6085.

27. Landry K, Thomas AA. Neurological Complications of CAR T Cell Therapy. Curr Oncol Rep 2020;22:83.

28. Gardner RA, Ceppi F, Rivers J, et al. Preemptive mitigation of CD19 CAR T-cell cytokine release syndrome without attenuation of antileukemic efficacy. Blood 2019;134:2149-58.

29. Taraseviciute A, Tkachev V, Ponce R, et al. Chimeric Antigen Receptor T Cell-Mediated Neurotoxicity in Nonhuman Primates. Cancer Discov 2018;8:750-63. 